\title{
Experimental and Theoretical Study of Corrosion Inhibition of Mild Steel in 1.0 M HCl Medium by 2(-4( hloro phenyl-1H- benzo[d]imidazol)-1-yl)phenyl)methanone
}

\author{
Omar Fergachi ${ }^{a}$, Fouad Benhiba ${ }^{e}$, Mohamed Rbaa $^{b}$, Rachid Touir ${ }^{a, d, *}\left({ }^{*}\right.$, Moussa Ouakkic, \\ Mohsine Galai ${ }^{a}$, Brahim Lakhrissi ${ }^{b}$, Hassan Oudda ${ }^{e}$,Mohamed Ebn Touhami ${ }^{a}$ \\ ${ }^{a}$ Laboratoire d'Ingénierie des Matériaux et d'Environnement: Modélisation et Application, Faculté des \\ Sciences, Université Ibn Tofail, BP 133, Kénitra 14000, Morocco. \\ ${ }^{b}$ Laboratory Agro-Resources, Polymers and Process Engineering, Department of Chemistry, Faculty of \\ Sciences, Ibn Tofail University, PO Box 133, 14000, Kénitra, Morocco. \\ 'Laboratoire de Matériaux, d'Electrochimie et d'Environnement (LMEE), Département de Chimie, \\ Faculté des Sciences, Université Ibn Tofail, Kénitra, Morocco. \\ ${ }^{d}$ Centre Régional des Métiers de l'Education et de la Formation, Avenue Allal AlFassi, Madinat AlIrfane \\ BP 6210 Rabat, Morocco. \\ ${ }^{e}$ Laboratoire des Procédés de Séparation, Faculté des Sciences, BP 242, Kénitra, Morocco
}

Received: November 23, 2017; Revised: July 16, 2018; Accepted: September 28, 2018

The 2(-4(chloro phenyl-1H- benzo[d]imidazol)-1-yl)phenyl)methanone (CBIPM) was synthesized and tested as a corrosion inhibitor for mild steel in $1.0 \mathrm{M} \mathrm{HCl}$ solution using electrochemical and spectroscopy measurements. Results obtained showed that this compound has a good inhibition properties for mild steel corrosion in acidic medium which its inhibition efficiency value reaches 98.9 $\%$ at $10^{-3} \mathrm{M}$. So, the potentiodynamic polarization curves showed that the CBIPM has a mixed type inhibitor. In addition, it is shown that the obtained results were confirmed by the UV-vis spectroscopic measurements. It is found that the inhibitor forms a complex with $\mathrm{Fe}^{2+}$ ion. On the other hand, the experimental results were completed by quantum chemical calculations using DFT method at the B3LYP/6-31G* level of theory. It is found that the theoretical and experimental results are in good agreement.

Keywords: CBIPM, Corrosion inhibition, Acidic medium, Electrochemical and spectroscopy measurements, DFT method.

\section{Introduction}

Mild steel and its alloy have many industrial applications because of its easy availability, low cost, uncomplicated fabrication of it into water pipe lines ${ }^{1,2}$, cooling water systems $^{3}$, boilers, etc... However, they are susceptible to different forms of corrosion inducted by several mediums. So, hydrochloric acid is the most difficult of the common acids to handle from the standpoints of corrosion and materials of constructions. Extreme care is required in the selection of materials to handle the acid by itself, even in relatively dilute concentrations or in process solutions containing appreciable amounts of hydrochloric acid. This acid is very corrosive to most of the common metals and alloys ${ }^{4}$.

However, various protection methods have been adopted; one of the frequently used measures is the use of organic compounds containing nitrogen, oxygen and sulphur atoms $\mathrm{s}^{5-10}$. These compounds either can form a strong co-ordination bond with metal atom or a passive film on the metal surface ${ }^{11}$. It is still a continuous search for better or blend inhibitors to meet the demand of the industries. Hence, the benzimidazole derivatives are among the heterocyclic compounds which

"e-mail: touir8@yahoo.fr or touir8@gmail.com have more attention due to their applications in such varied fields as medicine. Indeed, it has been shown that the benzimidazole derivatives have an activity antimicrobial analgesic and anti-inflammatory ${ }^{12}$ and have a good corrosion inhibition ${ }^{13}$. The selection criteria for various inhibitors include low concentration, stability in recirculation, cost effectiveness and low operational hazard.

We report here the effect of 2(-4( chloro phenyl-1Hbenzo[d]imidazol)-1-yl) phenylmethanone (CBIPM) addition, as a corrosion inhibitor for mild steel in $1.0 \mathrm{M}$ using electrochemical and spectroscopy measurements. Indeed, we studied the correlation between the quantum chemical calculations and molecular structure.

\section{Experimental Procedure}

\subsection{Materials}

Corrosion tests were performed on mild steel which had the following chemical composition (wt. \%) balanced with Fe: C 0.11; Si 0.24; Mn 0.47; Cr 0.12; Mo 0.02; Ni $0.10 ; \mathrm{Al} 0.03 ; \mathrm{Cu} 0.14 ; \mathrm{Co}<0.0012 ; \mathrm{V}<0.003$ and $\mathrm{W}$ 0 . 06 . The electrolysis cell was a pyrex of cylinder closed 
by cap containing five openings. Three of them were used for the electrodes. Before each experiment, the electrode was polished using emery paper from 40 to 1200 grades. After this, the electrode was cleaned with distillate water.

The corrosive solution $(1.0 \mathrm{M} \mathrm{HCl})$ was prepared by dilution of Analytical Grade $35 \% \mathrm{HCl}$ with distilled water and the temperature solution was adjusted to $298 \pm 2 \mathrm{~K}$.

The used inhibitor was 2(-4( chloro phenyl-1H- benzo[d] imidazol)-1-yl)phenylmethanone (CBIPM) which its molecular structure is shown in Figure 1.

The spectro-photometric method was carried out on the prepared mild steel samples after immersion in $1.0 \mathrm{M} \mathrm{HCl}$ without and with the addition of $10^{-3} \mathrm{M}$ of CBIPM at $298 \pm$ $2 \mathrm{~K}$ for 8 days. All the spectra measurements were carried out using a Beckman DU640 UV/Vis spectrophotometer.

\subsection{Electrochemical measurements}

The electrochemical measurements were carried out using Volta lab (Tacussel- Radiometer PGZ 100) and controlled by Tacussel corrosion analysis software model (Voltamaster 4) at under static condition. The corrosion cell used had three electrodes; the reference electrode was a saturated calomel electrode (SCE), the platinum electrode was used as auxiliary electrode of surface area of $2 \mathrm{~cm}^{2}$ and the working electrode was mild steel. All potentials given in this study were referred to this reference electrode. The working electrode was immersed in the test solution for $30 \mathrm{~min}$ to a establish steady state open circuit potential (Eocp). After measuring the $\mathrm{E}_{\text {ocp }}$, the electrochemical measurements were performed. All electrochemical tests have been performed in aerated solutions at $298 \pm 2 \mathrm{~K}$. The EIS experiments were conducted in the frequency range with high limit of $100 \mathrm{kHz}$ and different low limit $0.1 \mathrm{~Hz}$ at open circuit potential, with 10 points per decade, at the rest potential, after 30 min of acid immersion, by applying $10 \mathrm{mV}$ ac voltage peak-to-peak. Nyquist plots were made from these experiments. In order to extract the electrochemical parameters, the Z-view software was used.

After the AC impedance test, the potentiodynamic polarization measurements of mild steel substrate in inhibiting

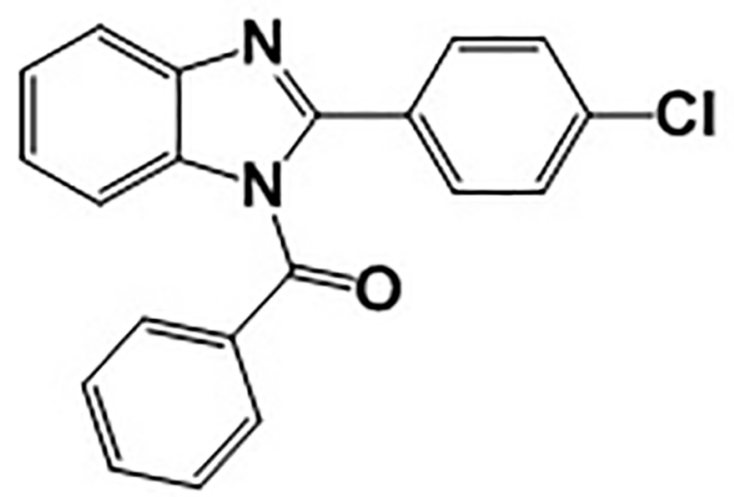

Figure 1. Molecular structure of 2(-4(chloro phenyl-1H- benzo[d] imidazol)-1-yl) phenylmethanone (CBIPM). and uninhibited solution were scanned from cathodic to the anodic direction between $-900 \mathrm{mV}$ to $-150 \mathrm{mV}$, with a scan rate of $1 \mathrm{mV} \mathrm{s}^{-1}$. The potentiodynamic data were analysed using the polarization VoltaMaster 4 software. The linear Tafel segments of anodic and cathodic curves were extrapolated to the corrosion potential to obtain corrosion current densities $\left(\mathrm{i}_{\text {corr }}\right)$. From the polarization curves obtained, the corrosion current $\left(\mathrm{i}_{\text {corr }}\right)$ was calculated by curve fitting using the equation ${ }^{14}$ :

$i=i_{a}+i_{c}=i_{\text {corr }}\left\{\begin{array}{l}\exp \left[b_{a} \times\left(E-E_{\text {corr }}\right)\right]- \\ \exp \left[b_{c} \times\left(E-E_{\text {corr }}\right)\right]\end{array}\right\}$

where $i_{\text {corr }}$ is the corrosion current density $\left(\mathrm{A} \mathrm{cm}^{-2}\right)$, $\mathrm{b}_{\mathrm{a}}$ and $\mathrm{b}_{\mathrm{c}}$ are the Tafel constants of anodic and cathodic reactions $\left(\mathrm{V}^{-1}\right)$, respectively. These constants are linked to the Tafel slopes $\beta(\mathrm{V} / \mathrm{dec})$ in usual logarithmic scale given by equation (2):

$$
\beta=\frac{\ln 10}{b}=\frac{2.303}{b}
$$

The inhibition efficiency was evaluated from the measured $\mathrm{i}_{\text {corr }}$ values using the following relationship:

$$
\eta_{P P}=\frac{i_{c o r r}^{0}-i_{c o r r}}{i_{c o r r}^{0}} \times 100
$$

where $\mathrm{i}_{\text {corr }}^{0}$ and $\mathrm{i}_{\text {corr }}$ are the corrosion current densities for steel electrode in the uninhibited and inhibited solutions, respectively.

From the impedance measurements, the inhibition efficiencies, $\eta_{\text {EIS }}$, were calculated from the $R_{c t}$ values at different concentrations using the following equation:

$$
\eta_{E I S}=\frac{R_{c t}-R_{c t}^{0}}{R_{c t}} \times 100
$$

where $\mathrm{R}^{0}$ at and $\mathrm{R}_{\mathrm{ct}}$ are the charge transfer resistance values in the absence and presence of inhibitor, respectively

\section{3 Computational procedures}

The quantum chemical calculations were carried out to elucidate the correlation between the inhibitor molecular structure and its efficiency. Quantum chemical calculations were performed using density functional theory (DFT) with the Beck's three parameter exchange functional along with the Lee-Yang-Parr non local correlation functional (B3LYP) with 6-31G $(\mathrm{d}, \mathrm{p})$ basis set implemented in Gaussian 09 program package ${ }^{15-17}$. This approach is widely utilized in the analysis of the characteristics of corrosion process. The geometry optimization of the CBIPM inhibitor was carried out in the gaseous phase.

The following quantum descriptors were calculated from the obtained optimized structure: energy of highest occupied molecular orbital $\left(\mathrm{E}_{\text {номо }}\right)$, energy of lower unoccupied molecular orbital $\left(\mathrm{E}_{\text {LUMO }}\right)$, electronegativity $(\chi)$, the global hardness $(\eta)$, global softness $(\sigma)$, electron affinity $(A)$, 
ionization potential $(\mathrm{Pi})$, the total molecular dipole moment $(\mu)$ and the total energy (TE) have been calculated ${ }^{18-23}$.

$$
\begin{gathered}
\eta=\frac{\Delta E}{2}=\frac{E_{L U M O}-E_{\text {HоMO }}}{2} \\
\sigma=\frac{1}{\eta}=-\frac{2}{E_{\text {HОMO }}-E_{\text {LUMO }}} \\
A=-E_{\text {LUMO }} \\
\omega=\frac{\mu^{2}}{2 \eta}
\end{gathered}
$$

where $\mu$ is the electronic chemical potential, such as: $\mu=-\chi^{2}$.

This index measures the propensity of chemical species to accept electrons. A good more reactive nucleophile is characterized by a lower value of $\mu, \omega$.

The number of transferred electrons $(\Delta \mathrm{N})$ was calculated as follows ${ }^{24}$ :

$$
\Delta N=\frac{\chi_{F e}-\chi_{i n h}}{2\left(\eta_{F e}+\eta_{i n h}\right)}
$$

where $\chi_{\mathrm{Fe}}$ and $\chi_{\text {inh }}$ respectively represent the absolute electronegativity of iron and the inhibitor molecule, $\eta_{\mathrm{Fe}}$ and $\eta_{\text {inh }}$ denote respectively the absolute hardness of iron and the molecule of inhibitor. The theoretical value of $\chi_{\mathrm{Fe}}=7.0 \mathrm{eV}$ and $\eta_{\mathrm{Fe}}=0$ is used to calculate the number of electrons transferred ${ }^{25}$.

\section{Results and Discussion}

\subsection{Open circuit potential versus time}

Figure 2 illustrates the variation of open circuit potential $\left(\mathrm{E}_{\mathrm{OCP}}\right)$ of mild steel in $1.0 \mathrm{M} \mathrm{HCl}$ with time without and with different concentration of CBIPM. It is observed that the

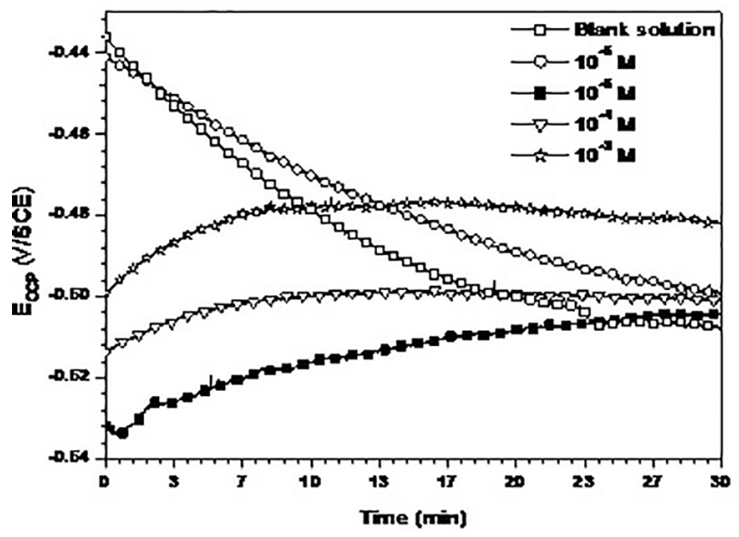

Figure 2. Evolution of EOCP versus time for mild steel in $1.0 \mathrm{HCl}$ without and with different concentrations of CBIPM. potential for uninhibited solution decreases with time and stabilizes at value of $-507 \mathrm{mV} / \mathrm{SCE}$ after 30 minutes. This phenomenon can be explained by the degradation of the mild steel with a formation of corrosive products on its surface. So, in the presence of CBIPM at the concentration range from $10^{-5} \mathrm{M}$ to $10^{-3} \mathrm{M}$, the potential shifts in the anodic direction (ennobling of potential) and stays quickly stable with time. This phenomenon can be explained by the formation of a protective film on the metallic surface.

\subsection{Potentiodynamic polarization curves}

The polarization behaviour of mild steel in $1.0 \mathrm{M} \mathrm{HCl}$ containing different concentrations of CBIPM is shown in Figure 3. Their extracted electrochemical parameters are given in Table 1. These results show that the CBIPM brings down the $i_{\text {corr }}$ value at all concentrations suggesting that this compound is an effective corrosion inhibitor. Moreover, it is noted that CBIPM causes a slight shift of $\mathrm{E}_{\text {corr }}$ to negative values with a decrease in the anodic and cathodic branches indicating that it is a mixed type inhibitor. It is remarked also that the CBIPM addition, changes the anodic $\left(\beta_{\mathrm{a}}\right)$ and cathodic Tafel $\left(\beta_{\mathrm{c}}\right)$ slopes conducting a change in iron dissolution and hydrogen evolution mechanisms which can be explained firstly by the adsorption of CBIPM molecules onto the metallic surface and blocked the reaction sites.

On the other hand, for higher than $-0.300 \mathrm{~V} / \mathrm{SCE}$ approximately, the various polarization curves tend to converge, with higher currents densities. This convergence is often explained by the fact that at high anodic potentials, the compounds are desorbed on the metallic ${ }^{27,28}$.

\subsection{Electrochemical impedance spectroscopy}

The impedance diagrams of mild steel in $1.0 \mathrm{M} \mathrm{HCl}$ at the open circuit potential $\left(\mathrm{E}_{\mathrm{OCP}}\right)$ containing different concentrations of CBIPM are shown in Figure 4. It is apparent from these diagrams that they composed in all cases from one capacitive loop which its diameter increases with the CBIPM concentration. The results can be interpreted using

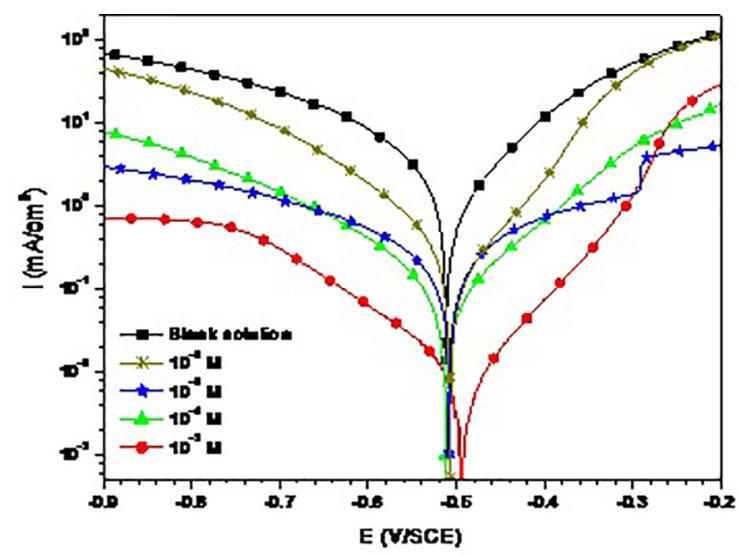

Figure 3 . Potentiodynamic polarization curves of mild steel in 1.0 $\mathrm{M} \mathrm{HCl}$ containing different concentration of CBIPM. 
Table 1. Electrochemical parameters for mild steel in $1.0 \mathrm{M} \mathrm{HCl}$ containing different concentrations of CBIPM

\begin{tabular}{ccccccc}
\hline & $\mathrm{C}(\mathrm{M})$ & $\mathrm{E}^{\mathrm{corr}}(\mathrm{mV} / \mathrm{SCE})$ & $\mathrm{i}^{\mathrm{corr}}\left(\mu \mathrm{A} / \mathrm{cm}^{2}\right)$ & $\beta_{\mathrm{c}}(\mathrm{mV} / \mathrm{dec})$ & $\beta_{\mathrm{a}}(\mathrm{mV} / \mathrm{dec})$ & $\eta_{\mathrm{PP}}(\%)$ \\
\hline & 00 & -510 & 2170 & -231 & 134 & - \\
BlankCBIPM & $10^{-3}$ & -491 & 23 & -145 & 81 & 98.9 \\
& $10^{-4}$ & -509 & 145 & -181 & 111 & 93.3 \\
& $10^{-5}$ & -503 & 427 & -170 & 143 & 80.3 \\
& $10^{-6}$ & -502 & 498 & -149 & 71 & 77 \\
\hline
\end{tabular}

However, the high inhibition efficiency of CBIPM, was attributed to the presence of the electron donor group (Chloro phenyl) in its structure. So, the adsorption of CBIPM molecules on the metallic surface can occur either directly on the basis of donor-acceptor interactions between the $\pi$-electrons of the ring and the vacant d-orbital of mild steel surface atoms or an interaction of organic nitrogen compounds with already adsorbed groups as proposed in the literature ${ }^{26}$.

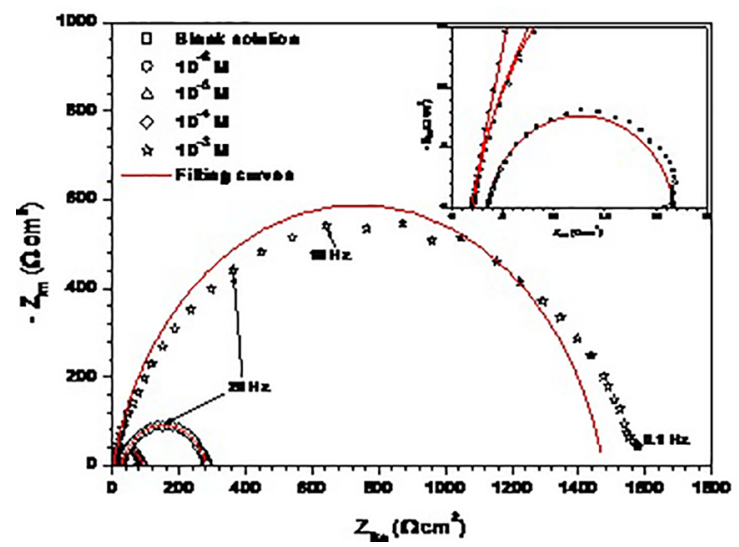

Figure 4. Nyquist plots for mild steel in $1.0 \mathrm{M} \mathrm{HCl}$ in the presence of different concentrations of CBIPM at the open circuit (EOCP).

equivalent electrical circuit presented in Figure 5, which has been used previously to model the iron/acid interface? Various parameters such as charge-transfer resistance $\left(\mathrm{R}_{\mathrm{ct}}\right)$ and double layer capacitance $\left(\mathrm{C}_{\mathrm{dl}}\right)$ obtained from impedance measurements are shown in Table 2. It is noted that the inhibitor addition improves $\mathrm{R}_{\mathrm{ct}}$ values and brings down $\mathrm{C}_{\mathrm{dl}}$ values. These observations clearly bring out the fact that the mild steel corrosion in $1.0 \mathrm{M} \mathrm{HCl}$ is controlled by a

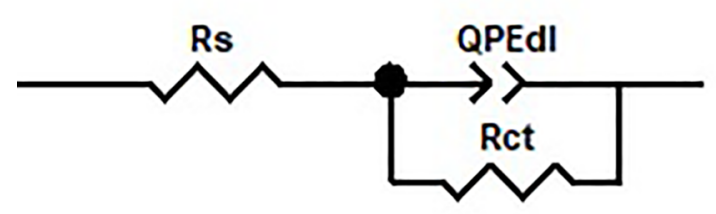

Figure 5. Proposed equivalent electrical circuit for mild steel/ $\mathrm{HCl}$ interface. charge transfer process and the corrosion inhibition occurs through the adsorption of CBIPM molecules on mild steel surface. Decrease in the $\mathrm{C}_{\mathrm{dl}}$ values, which can result from a decrease in local dielectric constant and/or an increase in current density, the thickness of the electrical double layer, suggested that the CBIPM molecules function by adsorption at the metal-solution interface ${ }^{29,30}$.

It is remarked also that the $\mathrm{n}_{\mathrm{dl}}$ values increase with increasing of the inhibitor concentrations. This can be explained by the decrease in surface heterogeneity as a result of the CBIPM molecules adsorption on the mild steel surface. The same result was found by other authors, and they explained by the molecule adsorption of inhibitors via $\mathrm{N}$ and $\mathrm{S}$ atoms in the inhibitor molecules ${ }^{31,32}$. In the same way, the relaxation time constant $\left(\tau_{\mathrm{dl}}\right)$ values increase with inhibitor concentration as well and the time of adsorption process becomes therefore much higher which means a slow adsorption process ${ }^{33}$. This shows that there is an agreement between the amount of charge that can be stored (that is capacitance) and discharge velocity in the interface $\left(\tau_{\mathrm{d} 1}\right)^{34}$.

In the other hand, it is observed that the electrolyte solution increases with the inhibitor addition. This can be explained by the protonation of the inhibitor molecules decreasing therefore the concentration of the $\mathrm{H}^{+}$ions in the solution.

\subsection{Effect of temperature solution}

To investigate the inhibition mechanism and to calculate the activation energies of the corrosion process, Potentiodynamic polarization measurements were taken out at various temperatures range $298-328 \mathrm{~K}$ in the absence and presence of inhibitor at $10^{-3} \mathrm{M}$ of CBIPM and at 30 minutes of immersion. The obtained results are presented in Figure 6 and 7 and their corresponding data are shown in Table 3.

Table 2. Fitting results of EIS for mild steel in $1.0 \mathrm{M} \mathrm{HCl}$ in the absence and presence of different concentrations of CBIPM.

\begin{tabular}{ccccccccc}
\hline & $\mathrm{C}(\mathrm{M})$ & $\mathrm{R}_{\mathrm{s}}\left(\Omega \mathrm{cm}^{2}\right)$ & $\mathrm{R}_{\mathrm{ct}}\left(\Omega \mathrm{cm}^{2}\right)$ & $\mathrm{C}_{\mathrm{dl}}\left(\mu \mathrm{F} \mathrm{cm}{ }^{-2}\right)$ & $\tau_{\mathrm{ct}}(\mathrm{ms})$ & $\mathrm{n}_{\mathrm{ct}}$ & $\eta_{\mathrm{EIS}} \%$ \\
\hline & 00 & $3.39 \pm 0.05$ & $18.42 \pm 0.25$ & $58.56 \pm 2.71$ & 1.08 & $0.78 \pm 0.01$ & - \\
& $10^{-6}$ & $1.89 \pm 0.04$ & $77.09 \pm 1.52$ & $33.72 \pm 1.52$ & 2.60 & $0.88 \pm 0.01$ & 86 \\
\multirow{2}{*}{ CBIPM } & $10^{-5}$ & $2.09 \pm 0.04$ & $87.32 \pm 1.64$ & $34.32 \pm 1.50$ & 2.99 & $0.89 \pm 0.01$ & 88 \\
& $10^{-4}$ & $25.8 \pm 0.11$ & $257.70 \pm 1.28$ & $17.39 \pm 1.97$ & 4.48 & $0.89 \pm 0.01$ & 89 & 92 \\
\hline
\end{tabular}



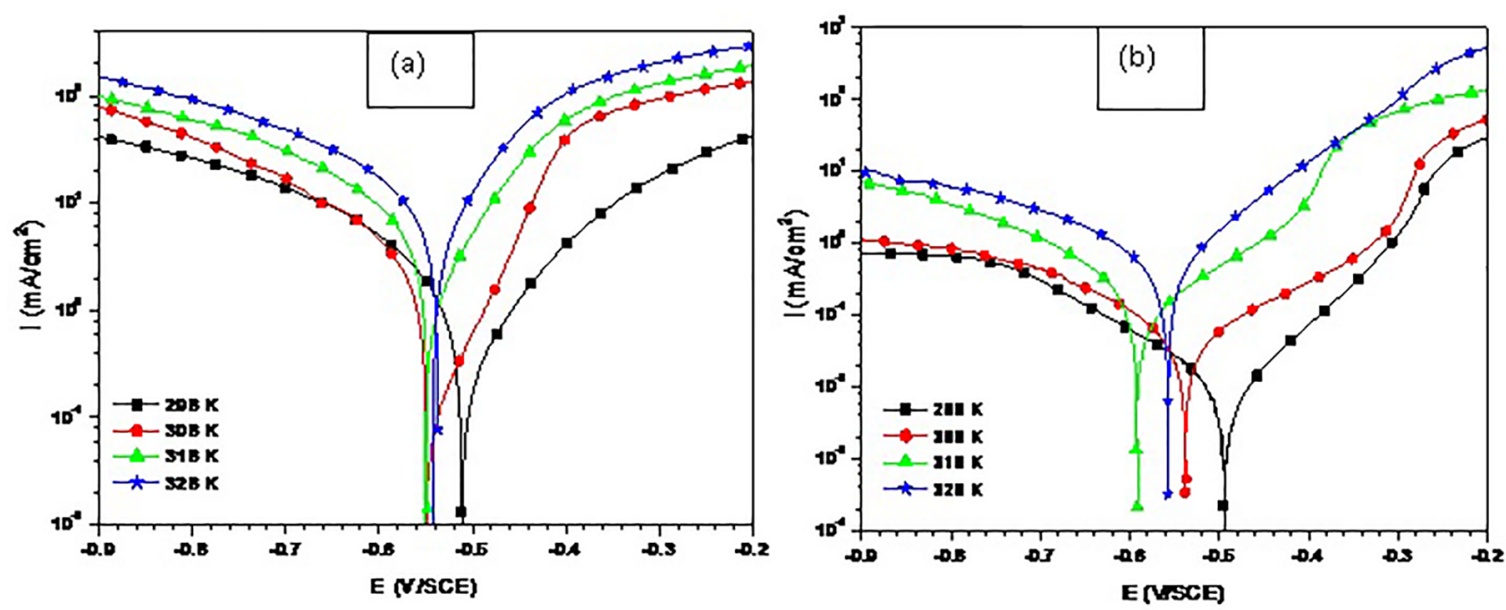

Figure 6. Potentiodynamic polarization curves for mild steel in $1.0 \mathrm{M} \mathrm{HCl}$ (a) without and (b) with CBIPM at different temperatures.

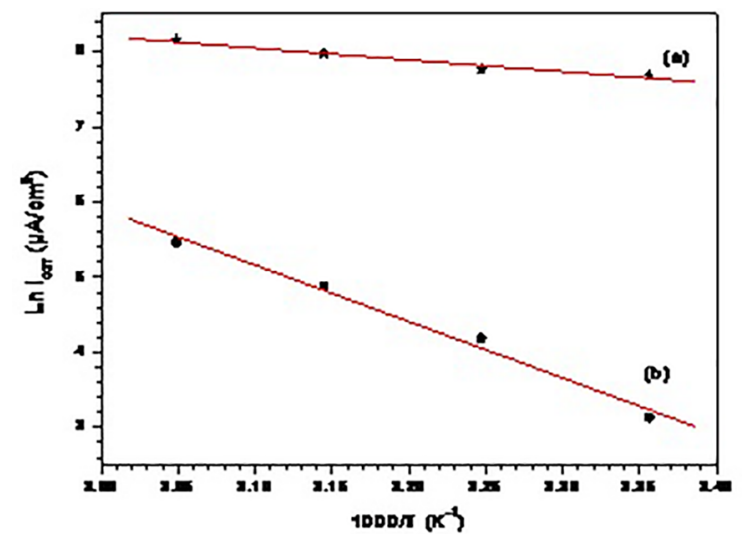

Figure 7. The relationship between $\mathrm{Ln}$ icorr and $1 / \mathrm{T}$ for mild steel in $1.0 \mathrm{M} \mathrm{HCl}$ in (a) the absence and (b) the presence of $10-3 \mathrm{M}$ of CMBIM.

It is noted that the $\mathrm{i}_{\text {corr }}$ increases with temperature solution in the absence and increases slightly in the presence of $10^{-3}$ $\mathrm{M}$ of CBIPM. This can be explained that the dissolution of mild steel is more important than in the presence of inhibitor. In addition, the activation energy for the corrosion process was estimated from Arrhenius type plot according to the following equation and its transition state:

$$
\begin{gathered}
i_{\text {corr }}=A \exp \left(\frac{-E_{a}}{R T}\right) \\
i_{\text {corr }}=\frac{R T}{N h} \exp \left(\frac{\Delta S_{a}}{R}\right) \exp \left(-\frac{\Delta H_{a}}{R T}\right)
\end{gathered}
$$

where $\mathrm{E}_{\mathrm{a}}$ is the apparent activation energy, $\mathrm{A}$ is the Arrhenius factor, $\mathrm{R}$ is the universal gas constant, $\mathrm{T}$ is the absolute temperature, $\mathrm{N}$ is the Avogadro's constant, $\mathrm{h}$ is the Plank's constant, $\Delta S_{a}$ is the entropy of activation and $\Delta H_{a}$ is the enthalpy of activation.

It can be seen that the inhibition efficiency of CBIPM was reduced at a higher temperature solution, suggesting that the adsorption mechanism of CBIPM molecules on metallic surface is physical adsorption ${ }^{35,36}$.

However, Figure 7 presents the obtained plots for the mild steel in $1.0 \mathrm{M} \mathrm{HCl}$, without and with $10^{-3} \mathrm{M}$ of CBIPM addition. It is found that the activation energy $\mathrm{E}_{\mathrm{a}}$ value increases from $13.0 \mathrm{~kJ} \mathrm{~mol}^{-1}$ to $62.5 \mathrm{~kJ} \mathrm{~mol}^{-1}$ with $10^{-3} \mathrm{M}$ of CBIPM addition. The change of the values of the apparent activation energies may be explained by the modification of the mechanism of the corrosion process in the presence of adsorbed inhibitor molecules ${ }^{28}$. In addition the increase of the $\mathrm{E}_{\mathrm{a}}$ probably was attributed to its physic-sorption on the mild steel surface $\mathrm{s}^{35,36}$.

Table 3. Electrochemical parameters of mild steel in $1.0 \mathrm{M} \mathrm{HCl}$ without and with $10^{-3} \mathrm{M}$ of CBIPM at different temperatures.

\begin{tabular}{llccccc}
\hline & $\mathrm{T}(\mathrm{K})$ & $\mathrm{E}_{\text {corr }}(\mathrm{mV} / \mathrm{SCE})$ & $\mathrm{i}_{\text {corr }}\left(\mu \mathrm{A} / \mathrm{cm}^{2}\right)$ & $\beta_{\mathrm{c}}(\mathrm{mV} / \mathrm{dec})$ & $\beta_{\mathrm{a}}(\mathrm{mV} / \mathrm{dec})$ & $\eta_{\mathrm{PP}}(\%)$ \\
\hline \multirow{3}{*}{ Blank solution } & 298 & -510 & 2170 & -231 & 134 & - \\
& 308 & -547 & 2358 & -212 & 53 & - \\
& 318 & -546 & 2894 & -156 & -153 & - \\
$10^{-3} \mathrm{M}$ of & 328 & -534 & 3468 & -145 & 81 & 98.9 \\
CBIPM & 298 & -491 & 23 & -207 & 155 & 97.2 \\
& 308 & -533 & 132 & -185 & 112 & 95.4 \\
\hline
\end{tabular}


On the other hand, the plots of $\ln \left(\frac{i_{\text {corr }}}{T}\right)$ against 1/T (Figure 8) should give a straight line with a slope of $\left(-\frac{\Delta H_{a}}{R}\right)$ and intercept of $\left(\ln \left(\frac{R}{N h}\right)+\frac{\Delta S_{a}}{R}\right)$ and the obtained thermodynamic parameters are calculated. It is found that the sign of the enthalpy $\left(\Delta H_{a}\right)$ is positive which increases from $10.43 \mathrm{~kJ} \mathrm{~mol}^{-1}$ to $59.9 \mathrm{~kJ} \mathrm{~mol}^{-1}$ with $10^{-3} \mathrm{M}$ of CBIPM addition, indicating an endothermic nature of the mild steel dissolution $^{37}$. Thus, the largest negative value of $\Delta S_{a}$ for mild steel in $1.0 \mathrm{M} \mathrm{HCl}$, which decreases negatively from $-146.3 \mathrm{~J} \mathrm{~mol}^{-1} \mathrm{~K}^{-1}$ to $-16.45 \mathrm{~J} \mathrm{~mol}^{-1} \mathrm{~K}^{-1}$. This phenomenon suggested that a decrease in randomness occurred on going from reactants to the activated complex. The great negative values of entropies indicate that the activated complex in the rate determining step is an association rather than dissociation step meaning that a decrease in disordering takes place on going from reactants to the activated complex ${ }^{38,39}$.

\section{$3.5 U V$-Vis spectroscopic investigation}

UV-visible spectroscopy which used to study the absorption of electromagnetic radiation by chemical species on a part of the spectrum: in the ultraviolet (wave lengths of 200 to $400 \mathrm{~nm}$ ), the visible range (400 to $750 \mathrm{~nm}$ ) and the very near Infrared (750 to $1000 \mathrm{~nm})$. The UV-visible specter allow to a chemist in his laboratory to: identify an unknown compound; checking the purity of a known product by the absence of bands; to follow a reaction by studying the appearance or disappearance of reagents, intermediate products or species and to dose a mixture from the intensity of the peaks or the integration curves. Today, spectroscopy has a wide range of applications in research, industry and medical diagnostics ${ }^{40}$.

In order to confirm the possibility of the formation of CBIPM-Fe complex, UV-vis absorption spectra obtained from $1.0 \mathrm{M} \mathrm{HCl}$ solution containing $10^{-30} \mathrm{M}$ of CBIPM before and after 8 days of mild steel immersion are shown in Figure 9. It is remarked that the absorption spectrum of the solution containing $10^{-3} \mathrm{M}$ of CBIPM before the mild steel

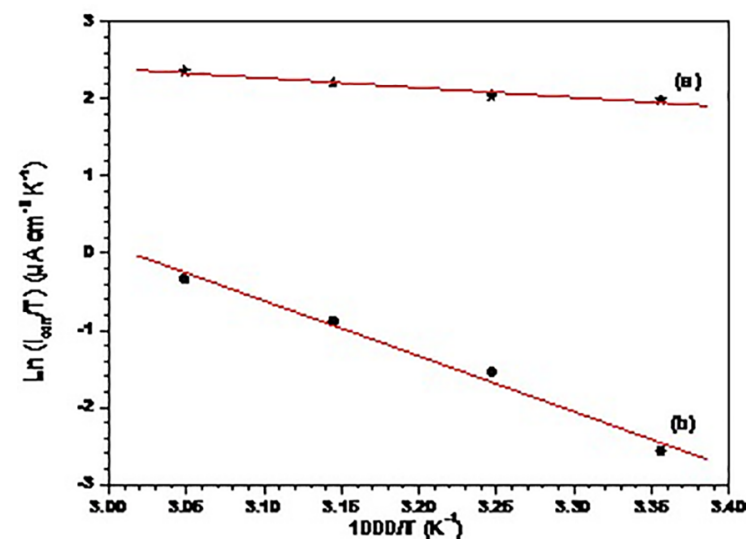

Figure 8. Transition Arrhenius plots for mild steel in $1.0 \mathrm{M} \mathrm{HCl}$ in (a) the absence and (b) the presence of $10^{-3} \mathrm{M}$ of CBIPM.

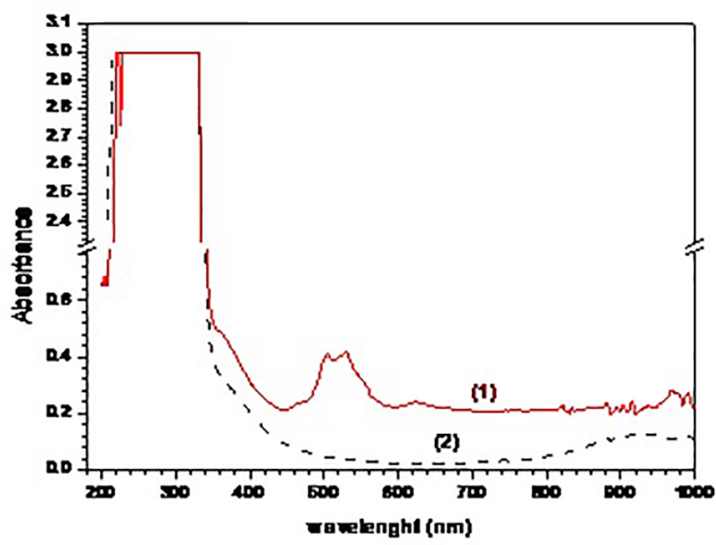

Figure 9. UV-visible spectra of the solution containing $10^{-3} \mathrm{M}$ of CMBIM (1) before the mild steel immersion and (2) after 8 days of mild steel immersion.

immersion (curve 1 ) shows a band of a high wavelength in the range of 200-300 $\mathrm{nm}$ (not indicated here) due to the $\pi-\pi *$ transition of the aromatic ring of compound and a short band at around 350 and $500 \mathrm{~nm}$ which is attributed to a $n-\pi^{*}$ electronic transition involving the lone pair of electrons on the chlorophenyl benzo[d]imidazol nitrogen atom.

After 8 days of mild steel immersion (curve 2), it is clearly seen that the band in the region of 200-300 nm is completely the same and the light deviation between $350-400 \mathrm{~nm}$ can be due to the $\mathrm{n}-\pi^{*}$ transition. In the mean time, there is an increase in the absorbance of this band. These experimental findings give a strong evidence for the possibility of the complex formation between $\mathrm{Fe}^{2+}$ cation and CBIPM in 1.0 M HCl solution. The same result was already confirmed by the literature studies ${ }^{41,42}$.

\subsection{Quantum calculation}

\subsubsection{Calculation of the main quantum parameters}

The experimental study was completed by a theoretical study at the B3LYP/6-31G (d, p) level in order to correlate the results obtained from the experimental study with the molecular structure and electronic properties of CBIPM. So, the HOMO energy is often associated with the molecule's ability to give away its electrons to suitable vacant orbital. Thus, the increase in $\mathrm{E}_{\text {номо }}$ values facilitates adsorption by influencing the transfer process through the adsorbed layer. On the other hand, the LUMO energy gives information on the acceptance of electrons in the molecule. The decrease in the $\mathrm{E}_{\text {LUMO }}$ value is an indicator of the molecule's ability to accept electrons from the iron surface and the higher the inhibitory efficiency. According to the literature, it is well known that a good corrosion inhibitor is often the one that not only yields its electrons, but also that capable of accepting the electrons of the metal surface. In addition, the energy gap 
$\left(\Delta \mathrm{E}_{\text {gap }}\right)$ is another important parameter. So, the adsorption performance between the inhibitors and the metal surface increases with the decrease in the energy gap ${ }^{43}$.

The Molecular optimization, electron density distributions of the boundary molecular orbitals, HOMO and LUMO of the CBIPM inhibitor are presented in Figure 10.

From the Figure 10, it can be seen that the electron density of the HOMO site is located on the chemical surface of the CBIPM inhibitor. In addition, the electron density of the unoccupied molecular orbital (LUMO) is distributed to the phenyl methanone group of CBIPM. On the other hand, the calculated quantum parameters are summarized in Table 4.

From Table 4, it is shown that the CBIPM inhibitor has a high $\mathrm{E}_{\text {номо }}(-5.981 \mathrm{eV})$ energy and a low $\mathrm{E}_{\text {LUмо }}(-2.076 \mathrm{eV})$, as well as a low energy difference value $\Delta \mathrm{E}_{\text {gap }}(3.905 \mathrm{eV})$ between $\mathrm{E}_{\text {Hомо }}$ and $\mathrm{E}_{\text {LUMO }}$, which reinforces its inhibitory action on the mild steel surface. In addition, the dipole moment $(\mu)$ is the parameter most used to describe the polarity of a molecule ${ }^{44}$. It is clearly proved in the literature that molecules with high dipole moments are more reactive. In our study, the dipole moment value of CBIPM is 5.195 debyes, which is higher than the water molecule.

On the other hand, the chemical hardness $(\eta)$ and softness $(\sigma)$ are important chemical properties for measuring molecular stability and reactivity. So, the inhibition efficiency of adsorption increases with chemical reactivity, normally the molecule with the smallest hardness value should have the greatest inhibition efficiency ${ }^{45}$. The CBIPM inhibitor has good chemical reactivity with the metallic surface due to the increase in the softness value $\left(\sigma=0.512 \mathrm{eV}^{-1}\right)$ and the decrease in the hardness $(\eta=1.952 \mathrm{eV})$.

The fraction of electrons transferred from the inhibitor molecule to the metallic surface $(\Delta \mathrm{N})$ was also calculated in this work. According to the Lukovits study ${ }^{46}$, if the value of $\Delta \mathrm{N}<3.6$, the inhibition efficiency was judged to be good. In our case, the charge transfer rate is $\Delta \mathrm{N}=0.761$ $\mathrm{eV}$, it is lower than the limit value set by Lukovits. It can be concluded that the CBIPM has an inhibitory effect against corrosion of the metal.

However, the organic molecules that possess heteroatoms can be protonated in the acid medium. As a result, the molecule CBIPM has several centers, which are favorable to protonation as the atoms of chlorine, oxygen and nitrogen, but the last one who is considered the most favorable site for protonation. Therefore, the N7 nitrogen atom of CBIPM is able to receive the proton $\left(\mathrm{H}^{+}\right)$. The protonation of the studied molecule was carried out using the theory of DFT with all the bases 6-31 G (d,p).

Figure 11 shows the optimization and distribution of the electronic densities of the frontier molecular orbital (FMO) of the protonated CBIPM.

In order to see the influence of protonation on the chemical quantum descriptors of the CBIPM molecule, we grouped these indices in Table 5.

From this table, it is clear that the values of $\mathrm{E}_{\text {номо }}$ and of $\Delta \mathrm{N}$ decreased, which indicates that the electron donor power of the protonated molecule CBIPM is less important than that of the neutral molecule. Thus, the decrease of $\Delta \mathrm{E}_{\text {gap }}$ and the increase of the dipolar moment $(\mu)$ reflect the increase of the reactivity of our protonated molecule.

\subsubsection{Calculation of the atomic loads of Mulliken}

It has been reported that the more negative of the atomic charges of the adsorbed center are, the more easily the atom gives away its electrons to the unoccupied orbital of the metal $^{47}$. The distribution of the Mulliken charges and the

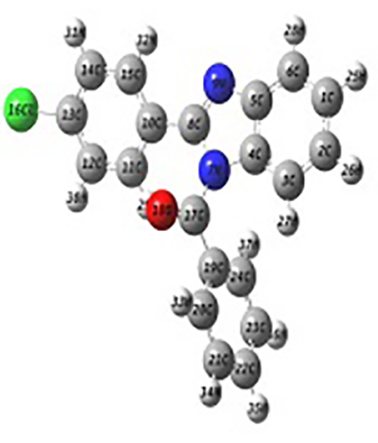

(a)

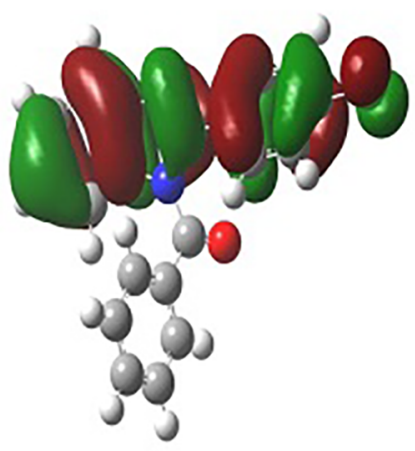

(b)

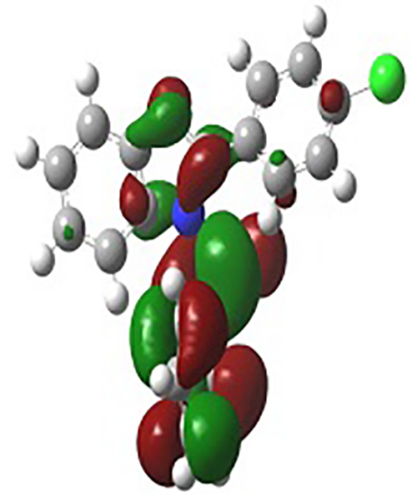

(c)

Figure 10. (a) Optimized molecular structure, (b) HOMO and (c) LUMO of the CBIPM molecule using DFT / B3LYP / 6-31 G (d, p).

Table 4. Molecular properties of CBIPM obtained from the optimized structure using DFT at the B3LYP/6-31G

\begin{tabular}{cccccccccccc}
\hline $\begin{array}{c}\mathrm{E}_{\text {Lumo }} \\
(\mathrm{eV})\end{array}$ & $\begin{array}{c}\mathrm{E}_{\text {Hомо }} \\
(\mathrm{eV})\end{array}$ & $\begin{array}{c}\Delta \mathrm{E} \\
(\mathrm{eV})\end{array}$ & $\begin{array}{c}\mu \\
(\text { debyes })\end{array}$ & $\begin{array}{c}\eta \\
(\mathrm{eV})\end{array}$ & $\begin{array}{c}\sigma \\
\left(\mathrm{eV}^{-1}\right)\end{array}$ & $\begin{array}{c}\mathrm{I} \\
(\mathrm{eV})\end{array}$ & $\begin{array}{c}\chi \\
(\mathrm{eV})\end{array}$ & $\begin{array}{c}\mathrm{A} \\
(\mathrm{eV})\end{array}$ & $\begin{array}{c}\Delta \mathrm{N} \\
(\mathrm{eV})\end{array}$ & $\begin{array}{c}\omega \\
(\mathrm{eV})\end{array}$ & $\begin{array}{c}\mathrm{TE} \\
(\mathrm{u} \mathrm{a})\end{array}$ \\
\hline-2.076 & -5.981 & 3.905 & 5.195 & 1.952 & 0.512 & 5.981 & 4.028 & 2.076 & 0.761 & 3.904 & -1414.924 \\
\hline
\end{tabular}




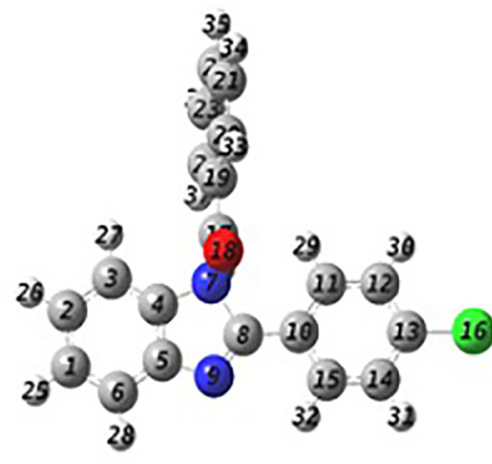

(a)

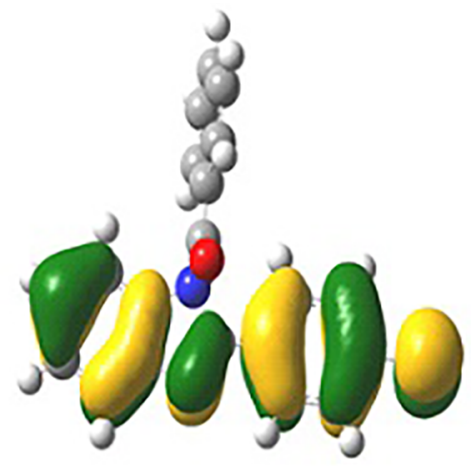

(b)

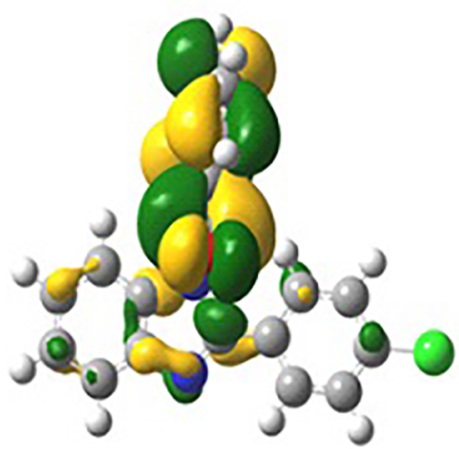

(c)

Figure 11. (a) Optimized molecular structure, (b) HOMO and (c) LUMO of the protonated CBIPM molecule.

Table 5. Calculated chemical quantum parameters of CBIPM protonated.

\begin{tabular}{cccccccccc}
\hline $\mathrm{E}_{\text {LUмо }}(\mathrm{eV})$ & $\mathrm{E}_{\text {Номо }}(\mathrm{eV})$ & $\Delta \mathrm{E}(\mathrm{eV})$ & $\mu$ (debyes) & $\eta(\mathrm{eV})$ & $\sigma\left(\mathrm{eV}^{-1}\right)$ & $\chi(\mathrm{eV})$ & $\Delta \mathrm{N}(\mathrm{eV})$ & $\omega(\mathrm{eV})$ & $\mathrm{TE}(\mathrm{u} \mathrm{a})$ \\
\hline-9.535 & -6.016 & 3.519 & 7.218 & 1.7595 & 0.568 & 7.7755 & -0.840 & 17.181 & -1415.258 \\
\hline
\end{tabular}

orientation of the polar moment are shown schematically in Figure 12 and the charge distribution values are also grouped in Table 6.

From Figure 12 and Table 6, it can be seen that the nitrogen, oxygen, and some carbon atoms have higher charge densities. The regions of the greatest electronic densities are generally the sites that electrophiles can attack through ${ }^{48}$. Thus, $\mathrm{N}, \mathrm{O}$, and some $\mathrm{C}$ atoms are the active centers that have the greatest ability to bind to the metal surface. On the other hand, some carbon atoms carry positive charges, and are the sites by which nucleophiles can attack. Therefore

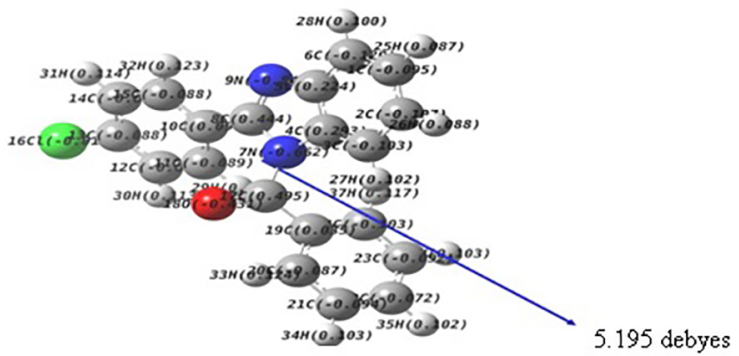

CBIPM can accept iron electrons through these atoms, these observations can be confirmed by the Fukui indices study.

\subsubsection{Fukui indices study}

Generally, the inhibitor molecules adsorb on the metallic surfaces by donor-acceptor interactions. This means that it is essential to analyze the atoms in the molecule that participate in this type of interaction. So, the condensed form of Fukui functions in a molecule with $\mathrm{N}$ electrons has been proposed by Yang and Mortier ${ }^{49}$ :

$f_{k}^{+}=P_{k}(N+1)-P_{k}(N) \quad$ for a nucleophilic attack $(11)$

$f_{k}^{-}=P_{k}(N)-P_{k}(N-1) \quad$ for electrophilic attack $(12)$

$P_{k}(N)$ : Electronic population of the atom $\mathrm{k}$ in the neutral molecule.

$P_{k}(N+1)$ : Electron population of the atom $\mathrm{k}$ in the anionic molecule.

Figure 12. Mulliken charge distribution of the CBIPM inhibitor.

Table 6. Mulliken charge distribution values of CBIPM molecule

\begin{tabular}{|c|c|c|c|c|c|c|c|c|}
\hline Atoms & $\mathrm{C} 1$ & $\mathrm{C} 2$ & $\mathrm{C} 3$ & $\mathrm{C} 4$ & $\mathrm{C} 5$ & C6 & N7 & $\mathrm{C} 8$ \\
\hline $\begin{array}{l}\text { Mulliken charge } \\
\text { distribution } \times 10^{-3}\end{array}$ & -94.850 & -107.059 & -103.299 & 293.250 & 223.607 & -119.657 & -661.989 & 444.433 \\
\hline Atoms & N9 & $\mathrm{C} 10$ & C11 & $\mathrm{C} 12$ & $\mathrm{C} 13$ & C14 & $\mathrm{C} 15$ & $\mathrm{Cl16}$ \\
\hline $\begin{array}{l}\text { Mulliken charge } \\
\text { distribution } \times 10^{-3}\end{array}$ & -546.838 & 96.984 & -88.611 & -82.625 & -88.397 & -80.751 & -87.746 & -18.677 \\
\hline Atoms & $\mathrm{C} 17$ & O18 & C19 & $\mathrm{C} 20$ & $\mathrm{C} 21$ & C 22 & $\mathrm{C} 23$ & $\mathrm{C} 24$ \\
\hline $\begin{array}{l}\text { Mulliken charge } \\
\text { distribution } \times 10^{-3}\end{array}$ & 495.385 & -430.912 & 34.952 & -87.133 & -94.254 & -71.857 & -91.643 & -102.804 \\
\hline
\end{tabular}


$P_{k}(N-1)$ : Electron population of the atom $\mathrm{k}$ in the cationic molecule.

Where $f_{k}^{+}$and $f_{k}^{-}$represent the ability of the $\mathrm{k}$ atom to react with a nucleophile and electrophile, respectively.

A high value of $f_{k}^{+}$shows that the $\mathrm{k}$ atom has an electrophilic character indicating a high probability for a nucleophilic attack on that site where the high value of $f_{k}^{-}$ means that the $\mathrm{k}$ site is more nucleophilic and available for the electrophilic attacks ${ }^{50,51}$. The calculated Fukui indices for the CBIPM molecule are shown in Table 7. It can be seen that the CBIPM inhibitor possesses the greatest values of $f_{k}^{+}$which are located on the atoms N9, C17, O18, C20, $\mathrm{C} 22$ and $\mathrm{C} 24$. These atoms participate in the acceptance of electrons from the metal surface. On the other hand, the atoms $\mathrm{C} 2, \mathrm{C} 4$ and $\mathrm{C} 116$ are the electron donors as atoms possess higher $f_{k}^{-}$values. Consequently, the theoretical results were found to be consistent with the experimental results for the corrosion inhibition of mild steel by the CBIPM inhibitor.

\section{Conclusion}

The corrosion inhibition of mild steel in $1.0 \mathrm{M} \mathrm{HCl}$ solution by CBIPM was studied using common electrochemical techniques coupled with UV-vis spectroscopic and quantum chemical calculations by DFT method. According to experimental and theoretical findings, it could be concluded that:

1. CBIPM is a good corrosion inhibitor for mild steel in $1.0 \mathrm{M} \mathrm{HCl}$ solution and its inhibition efficiency depends on its concentration.

2. Potentiodynamic polarization curves indicated that CBIPM acts as a mixed type inhibitor.

3. EIS plots indicated that $\mathrm{R}_{\mathrm{ct}}$ values increase and $\mathrm{C}_{\mathrm{dl}}$ values decrease with inhibitor concentration.

4. The UV-vis spectroscopic study clearly reveals the formation of Fe-CBIPM complex, which may be also responsible for the observed inhibition.

5. The theoretical results were found to be consistent with the experimental results for the corrosion inhibition of mild steel by the CBIPM inhibitor.

Table 7. The Fukui indices calculated for the CBIPM molecule using DFT / B3LYP / 6-31 G (d, p)

\begin{tabular}{lccccccccc}
\hline Atoms & $\mathrm{C} 1$ & $\mathrm{C} 2$ & $\mathrm{C} 3$ & $\mathrm{C} 4$ & $\mathrm{C} 5$ & $\mathrm{C} 6$ & $\mathrm{~N} 7$ & $\mathrm{C} 8$ \\
\hline$f_{k}^{+}$ & 0.011 & 0.01 & -0.007 & -0.004 & 0.006 & 0.012 & -0.029 & 0.014 \\
$f_{k}^{-}$ & 0.016 & 0.050 & 0.020 & 0.041 & 0.028 & 0.032 & 0.010 & 0.045 \\
Atoms & $\mathrm{N} 9$ & $\mathrm{C} 10$ & $\mathrm{C} 11$ & $\mathrm{C} 12$ & $\mathrm{C} 13$ & $\mathrm{C} 14$ & $\mathrm{C} 15$ & $\mathrm{C} 116$ \\
$f_{k}^{+}$ & 0.048 & -0.010 & -0.015 & 0.008 & 0.005 & 0.010 & 0.005 & 0.050 \\
$f_{k}^{-}$ & 0.054 & 0.014 & 0.022 & 0.021 & 0.019 & 0.017 & 0.021 & 0.128 \\
Atoms & $\mathrm{C} 17$ & $\mathrm{O} 18$ & $\mathrm{C} 19$ & $\mathrm{C} 20$ & $\mathrm{C} 21$ & $\mathrm{C} 22$ & $\mathrm{C} 23$ & $\mathrm{C} 24$ \\
$f_{k}^{+}$ & 0.136 & 0.131 & 0.002 & 0.047 & 0.009 & 0.064 & 0.012 & 0.044 \\
$f_{k}^{-}$ & -0.007 & 0.017 & -0.010 & 0.001 & 0.005 & 0.010 & 0.003 & -0.012 \\
\hline
\end{tabular}

\section{References}

1. Knowles PR. Design of Structural Steelwork. London: Surrey University Press; 1987.

2. Loto RT, Tobilola O. Corrosion inhibition properties of the synergistic effect of 4-hydroxy-3-methoxybenzaldehyde and hexadecyltrimethylammoniumbromide on mild steel in dilute acid solutions. Journal of King Saud University - Engineering Sciences. 2018;30(4):384-390.

3. Makrides AC, Hackerman N. Inhibition of Acid Dissolution of Metals. I. Some General Observations. The Journal of Physical Chemistry. 1955;59(8):707-710.

4. Fontana MG. Corrosion Engineering. 3rd ed. New York: McGrawHill; 1987.

5. El Kacimi Y,Azaroual MA, Touir R, Galai M,Alaoui K, Sfaira M, etal. Corrosion inhibition studies for mild steel in $5.0 \mathrm{MHCl}$ by substituted phenyltetrazole. Euro-Mediterranean Journal for Environmental Integration. 2017;2:1. DOI 10.1007/s41207-016-0011-8.

6. Hossini SMA, Salari M. Corrosion inhibition of stainless steel 302 by 1-methyl-3-pyridine-2-Yl-thiourea in acidic media. Indian Journal of Chemical Technology. 2009;16:480-485.

7. Shetty SD, Shetty P, Nayak HVS. The inhibition action of N-(furfuryl)$\mathrm{N}$-phenylthiourea on the corrosion of mild steel in acid media. Journal of the Serbian Chemical Society. 2006;71(10):1073-1082.

8. Gogoi PK, Sonowal J. Dimensional Stability, Thermal Degradation and Termite Resistant Studies of Chemically Treated Wood. International Journal of Chemistry. 2010;2(2):218-225.

9. Adardour K, Kassou O, Touir R, Ebn Touhami M, El Kafsaoui H Benzeid H, et al. Study of the influence of new quinoxaline derivatives on corrosion inhibition of mild steel in hydrochloric acidic medium. Journal of Materials and Environmental Science. 2010;1(2):129138. 
10. Quraishi MA, Rawat J. Inhibition of mild steel corrosion by some macrocyclic compounds in hot and concentrated hydrochloric acid. Materials Chemistry and Physics. 2002;73(2-3):118-122.

11. Hassan N, Holze R. A comparative electrochemical study of electrosorbed 2- and 4-mercaptopyridines and their application as corrosion inhibitors at C60 steel. Journal of Chemical Sciences. 2009;121(5):693-702.

12. Singh N, Pandurangan A, Rana K, Anand P, Ahamad A, Tiwari AK. Benzimidazole: A short review of their antimicrobial activities. International Current Pharmaceutical Journal. 2012;1(5):119-127.

13. Touir R, Belakhmima RA, Ebn Touhami M, Lakhrissi L, El Fayed M, Lakhrissi B, et al. Comparative inhibition study of mild steel corrosion in hydrochloric acid by benzimidazole derivatives. Journal of Materials and Environmental Science. 2013;4(6):921-930.

14. Touir R, Dkhireche N, Ebn Touhami M, Sfaira M, Senhaji O, Robin JJ, et al. Study of phosphonate addition and hydrodynamic conditions on ordinary steel corrosion inhibition in simulated cooling water. Materials Chemistry and Physics. 2010;122(1):19.

15. Frisch MJ, Trucks GW, Schlegel HB, Scuseria GE, Robb MA, Cheeseman JR, et al. Gaussian 03, Revision B.03. Pittsburgh: Gaussian; 2003.

16. Petersson GA, Bennett A, Tensfeldt TG, Al-Laham MA, Shirley WA, Mantzaris J. A complete basis set model chemistry. I. The total energies of closed-shell atoms and hydrides of the first-row elements. Journal of Chemical Physics. 1988;89(4):2193-2218.

17. Ansari KR, Quraishi MA. Experimental and quantum chemical evaluation of Schiff bases of isatin as a new and green corrosion inhibitors for mild steel in 20\% H2SO4. Journal of the Taiwan Institute of Chemical Engineers. 2015;54:145-154.

18. Neese F, Wennmohs F. ORCA, An ab Initio, DFT and semiempirical SCF-MO package, Version 2.9. Mulheim an der Ruhr: Max Planck Institute for Bioinorganic Chemistry; 2012.

19. Becke DA, Density functional calculations of molecular bond energies. Journal of Chemical Physics. 1986;84(8):45244529 .

20. Lee C, Yang W, Parr RG. Development of the Colle-Salvetti correlation-energy formula into a functional of the electron density. Physical Review B. 1988;37(2):785-789.

21. Saha SK, Hens A, RoyChowdhury A, Lohar AK, Murmu NC, Banerjee P. Molecular Dynamics and Density Functional Theory Study on Corrosion Inhibitory Action of Three Substituted Pyrazine Derivatives on Steel Surface. Canadian Chemical Transactions. 2014;2(4):489-503.

22. Saha SK, Ghosh P, Hens A, Murmu NC, Banerjee P. Density functional theory and molecular dynamics simulation study on corrosion inhibition performance of mild steel by mercaptoquinoline Schiff base corrosion inhibitor. Physica E: Lowdimensional Systems and Nanostructures. 2015;66:332-341.

23. Chermette H. Chemical reactivity indexes in density functional theory. Journal of Computational Chemistry. 1999;20(1):129154.
24. Pearson RG. Absolute electronegativity and hardness: application to inorganic chemistry. Inorganic Chemistry. 1988;27(4):734740 .

25. Parr RG, Pearson RG. Absolute hardness: companion parameter to absolute electronegativity. Journal of the American Chemistry Society. 1983;105(26):7512-7516.

26. El Faydy M, Galai M, Touir R, El Assyry A, Ebn Touhami M, Benali B, et al. Experimental and theoretical studies for steel $\mathrm{XC} 38$ corrosion inhibition in $1 \mathrm{M} \mathrm{HCl}$ by $\mathrm{N}$-(8-hydroxyquinolin5-yl)-methyl)-N-phenylacetamide. Journal of Materials and Environmental Science. 2016;7(4):1406-1416.

27. Bartos M, Hackerman N. A Study of Inhibition Action of Propargyl Alcohol during Anodic Dissolution of Iron in Hydrochloric Acid. Journal of the Electrochemical Society. 1992;139(12):3428-3433.

28. Laengle E, Hackerman N. Electrode Behavior of Iron in 2 $\mathrm{M} \mathrm{HCl} \mathrm{Containing} \mathrm{Oximes} \mathrm{or} \mathrm{Quinuclidine.} \mathrm{Journal} \mathrm{of} \mathrm{the}$ Electrochemical Society. 1971;118(8):1273-1278.

29. Kumari PP, Rao SA, Shetty P. Corrosion Inhibition of Mild Steel in $2 \mathrm{M} \mathrm{HCl}$ by a Schiff Base Derivative. Procedia Materials Science. 2014;5:499-507.

30. El-Hajjaji F, Zerga B, Sfaira M, Taleb M, Ebn Touhami M, Hammouti B, et al. Comparative Study of Novel N-Substituted Quinoxaline Derivatives towards Mild Steel Corrosion in Hydrochloric Acid: Part 1. Journal of Materials and Environmental Science. 2014;5(1):255-262.

31. Finšgar M, Merl DK. An electrochemical, long-term immersion, and XPS study of 2-mercaptobenzothiazole as a copper corrosion inhibitor in chloride Solution. Corrosion Science. 2014;83:164175.

32. El Bakri M, Touir R, Tazouti A, Dkhireche N, Ebn Touhami M, Rochdi A, et al. Corrosion Inhibition Study of Brass in Simulated Cooling Water by Triazole Derivatives, Cetyltrimethylammonium Bromide and Their Mixture. Arabian Journal for Science and Engineering. 2016;41(1):75-88.

33. Popova A, Christov M, Vasilev A. Mono- and dicationic benzothiazolic quaternary ammonium bromides as mild steel corrosion inhibitors. Part II: Electrochemical impedance and polarisation resistance results. Corrosion Science. 2011;53(5):17701777.

34. Khaled KF, Al-Qahtani MM. The inhibitive effect of some tetrazole derivatives towards $\mathrm{Al}$ corrosion in acid solution: Chemical, electrochemical and theoretical studies. Materials Chemistry and Physics. 2009;113(1):150-158.

35. Elewady GY. Pyrimidine Derivatives as Corrosion Inhibitors for Carbon-Steel in 2M Hydrochloric Acid Solution. International Journal of Electrochemical Science. 2008;3:1149-1161.

36. Ebenso EE. Effect of halide ions on the corrosion inhibition of mild steel in $\mathrm{H}_{2} \mathrm{SO}_{4}$ using methyl red - Part 1. Bulletin of Electrochemistry. 2003;19(5):209-216.

37. El Ouali I, Hammouti B, Aouniti A, Ramli Y, Azougagh M, Essassi EM, et al. Thermodynamic characterisation of steel corrosion in $\mathrm{HCl}$ in the presence of 2-phenylthieno (3, 2-b) quinoxaline. Journal of Materials and Environmental Science. 2010;1(1):1-8. 
38. Oguzie EE. Corrosion inhibition of aluminium in acidic and alkaline media by Sansevieria trifasciata extract. Corrosion Science. 2007;49(3):1527-1539.

39. Martinez S, Stern I. Thermodynamic characterization of metal dissolution and inhibitor adsorption processes in the low carbon steel/mimosa tannin/sulfuric acid system. Applied Surface Science. 2002;199(1-4):83-89.

40. Reljin IS, Reljin BD, Avramov-Ivic ML, Jovanovic DV, Plavec GI, Petrovic SD, et al. Multifractal analysis of the UV/VIS spectra of malignant ascites: Confirmation of the diagnostic validity of a clinically evaluated spectral analysis. Physica A: Statistical Mechanics and its Applications. 2008;387(14):3563-3573.

41. Song XQ, Wang YW, Zheng JR, Liu WS, Tan MY. Synthesis and spectroscopic properties of lanthanide nitrate complexes with a new amide-based quinoxaline-2,3-dione ligand. Spectrochimica Acta Part A: Molecular and Biomolecular Spectroscopy. 2007;68(3):701-704.

42. Abboud Y, Abourriche A, Saffaj T, Berrada M, Charrouf M, Bennamara A, et al. 2,3-Quinoxalinedione as a novel corrosion inhibitor for mild steel in $1 \mathrm{M} \mathrm{HCl}$. Materials Chemistry and Physics. 2007;105(2007):1-5.

43. Yildiz R. An electrochemical and theoretical evaluation of 4,6-diamino-2-pyrimidinethiol as a corrosion inhibitor for mild steel in $\mathrm{HCl}$ solutions. Corrosion Science. 2015;90:544-553.

44. Al Hamzi AH, Zarrok H, Zarrouk A, Salghi R, Hammouti B, AlDeyab SS, et al. The Role of Acridin- $9(10 \mathrm{H})$-one in the Inhibition of Carbon Steel Corrosion: Thermodynamic, Electrochemical and DFT Studies. International Journal Electrochemical Science. 2013;8(2013):2586-2605.
45. Ramya K, Mohan R, Joseph A. Adsorption and electrochemical studies on the synergistic interaction of alkyl benzimadazoles and ethylene thiourea pair on mild steel in hydrochloric acid. Journal of the Taiwan Institute of Chemical Engineers. 2014;45(6):30213032 .

46. Lukovits I, Kálmán E, Zucchi F. Corrosion Inhibitors-Correlation between Electronic Structure and Efficiency. Corrosion. 2001;57(1):38.

47. Obi-Egbedi N, Essien K, Obot I, Ebenso E. 1,2-Diaminoanthraquinone as Corrosion Inhibitor for Mild Steel in Hydrochloric Acid: Weight Loss and Quantum Chemical Study, International Journal Electrochemical Science. 2011;6:913-930.

48. Özcan M, Dehri I, Erbil M. Organic sulphur-containing compounds as corrosion inhibitors for mild steel in acidic media: correlation between inhibition efficiency and chemical structure. Applied Surface Science. 2004;236(1-4):155-164.

49. Yang W, Mortier WJ. The use of global and local molecular parameters for the analysis of the gas-phase basicity of amines. Journal of the American Chemical Society. 1986;108(19):57085711.

50. Jafari H, Sayin K. Electrochemical and theoretical studies of adsorption and corrosion inhibition of aniline violet compound on carbon steel in acidic solution. Journal of the Taiwan Institute of Chemical Engineers. 2015;56:181-190.

51. About H, El Faydy M, Rouifi Z, Benhiba F, Ramsis H, Boudalia $\mathrm{M}$, et al. Experimental and theoretical studies of 5-((4-phenyl-4,5dihydro-1H-tetrazol-1-yl)methyl)quinolin-8-ol quinoline derivative as effective corrosion inhibitor for mild steel in $1.0 \mathrm{M} \mathrm{HCl}$. Journal of Materials and Environmental Science. 2018;9(1):345-357. 